Proceedings of the 1st international conference Economic and Business Trends Shaping the Future | 2020

\title{
MEASURING THE EFFECT OF SALARY RAISE OVER THE PERFORMANCE OF SALES PROFESSIONALS - THE CASE OF AN INTERNATIONAL ORGANIZATION
}

\author{
Nena Dimovska \\ Faculty of Economics - Skopje, Ss Cyril and Methodius University \\ n.dimovska@hotmail.com \\ Ljupcho Eftimov \\ Faculty of Economics - Skopje, Ss Cyril and Methodius University \\ eftimov@eccf.ukim.edu.mk
}

\section{ABSTRACT}

Should fixed salary be the single and most appropriate tool for motivating employees; or should management consider a more diverse, innovative tools for motivation, based on multiple factors? Does a salary increase always guarantee ROI? Also, will sales professionals be motivated by an incremental, equal-to-all salary increase? This paper elaborates these and similar dilemmas and presents a research conducted in the sales sector, in a medium-sized international firm. It represents consequences of applying an equal and applicable to all salary increase of 10\%. The paper tries to reject traditional beliefs (and awards distribution models) that salary, per se, is the highest source or motivation and a guarantee for improving performance. The research shows how sales professionals are affected by incremental salary increase, and tries to provide recommendations for further research on effective, cost-efficient award strategies that increase motivation and performance and can be easily adopted in similar organizations.

Key words: Compensation and Benefits, Rewarding Sales Professionals, Motivation, KPIs

JEL classification: J33, M12. M52

\section{INTRODUCTION}

Probably no other aspect of compensation has attracted as much attention recently as rewarding sales professionals, as they make a meaningful and instantaneous impact on business results. They are taking a customer facing role and represent the firm's brand. That is the main reason why leaders often treat and reward them a bit differently from other employees.

There are many different methods of rewarding sales staff and rarely firms adopt a salary only approach. It is justified only when sales professionals have little influence over sales volume or when promoting products/services is more important than direct selling. Most organizations implement more complex reward methods such as basic salary plus commission, basic salary plus bonus, commission only or additional cash or non-cash rewards (Armstrong, 2010).

http://doi.org/10.47063/EBTSF.2020.0035

http://hdl.handle.net/20.500.12188/9717 
Upon creating compensation programs, managers should be aware that employees not only want decent pay and benefits, but they also want to be treated fairly and be valued for their input. Implementing the two basic principles (1) external equity (market salary competitiveness) and (2) internal equity (employees within an organization are paid fairly versus each other) is critical for their motivation and performance (Bojadzioski, Eftimov, 2009).

This paper is dedicated to the topic of employee awards and via evidence-based research, into an international firm, aims to prove that awarding all employees with relatively equal-to-all salary raise shall not positively affect neither employee performance nor productivity; especially sales professionals. The paper's objective is not aiming to prove that salary increase, in general, does not affect performance. On the contrary, both history and practice prove that it has positive influence over motivation, performance and positively reflects the organization, its brand, and attracting more competitive workforce - talents. (Dal Bo et al, 2013). Therefore, this research paper elaborates on the various tools of motivating sales professionals, as an utterly unique group, comprised in every organization.

Building a sales career is not characterized with stability or (easily) predictable growth, since one's career development and future are predominantly reliant on achieved results and individual input. Hence, a significant amount of these professionals' total compensation is consisted of a variable part i.e. commission or bonus per the achieved results. Hence, this paper's practical objective shows that for such professionals a minor equal-for-all salary raise (around 10\%), which does not consider individual working history, success and experience is not a proper solution to attract, retain, motivate or improve performance.

By conducting a studious analysis of similar research and literature withing this realm, one can elaborate that for sales and business development professionals a lot more appropriate strategies are those that include one's individual input, results, and achievements. When it comes to rewarding strategies, a "kaizen mindset" should be adopted, since it speaks volumes about the firm's culture and values. Thus, to sustain high motivation, it is critical to identify the appropriate tools and manners of recognizing one's individual work (Islam and Ismail, 2004). Professionals who are exceptional at their work, expect to be rightfully recognized and awarded by the management and their colleagues (Islam and Ismail, 2004). Taking myriad forms and approaches, awards are accepted in all organizations, regardless of the industry, size, private or public sectors. Hence, this paper aims to help shape these systems, as organizations risk to lose significant financial assets, if they fail to achieve the desired motivation and performance improvement objectives (Bowen, 2000).

In terms of the structure, the paper is comprised of three parts: the first is a brief overview of existing theory and elaborates on the topic's present-day relevance and significance; the second particularizes the research methodology and analyses the practice in one international organization, from the professional development industry; and lastly, it draws conclusions and shares practical recommendations for further research. 


\section{THEORETICAL BACKGROUND}

Contemporary business leaders and scholars hold utterly diverse opinions regarding employees' total compensation and rewards; notwithstanding the unwritten consensus they are probably the most complex and sensitive managerial responsibility. Surprisingly, there is lack of empirical research over the implementation and management of these systems, especially on the most appropriate manner of awarding and compensating employees. (Bradler et al., 2013). Contrary, there is some research available that analyzes the influence awards have over people's status and their motivation (Dubey and Geanakoplos, 2006; Ellingsen, Johannesson 2007; Frey, 2007; Moldovanu et al. 2007; Auriol, Renault 2008; Besley, Ghatak 2008; Ederer, Patacconi, 2008; Dur 2009).

Nevertheless, there is not too much practical research that explains awards and status in actual business context (Ball et al. 2001; Markham et al., 2002; Ariely et al., 2009) and there is almost no research available that shows how performance can be improved, only by receiving recognition, or improved social status in the organization. Even so, organizations benefit from the fact that salary, per se, is not the single factor that contributes to high job satisfaction, as compensation and reward systems, which are not aligned with the market standard, can have significant negative effects on the company's bottom line (Bryant, Allen, 2013)

Some empirical research, conducted in laboratory environment (Fehr et al. 1993 и 1997), as well as other short-term practical research (Falk, 2007) supports a rather more traditional model for the awards exchange. In number of cases, it can be proven that giving (and receiving) awards always has positive effect on performance, (Gibbons, 1997; Lazear, 2000) so it does not come as a surprise that managers are extremely dedicated on finding a perfect formula for properly awarding professionals for the jobs they are performing. There are plans which could be adopted to take a strategic approach for total compensation and awards, which are aligned within the organizational strategy, decrease employee turnover, are run by fair system of policies and procedures and manage employee expectations and perceptions for these systems. (Bryant and Allen, 2013).

Few traditional theories, more specifically the theories of expectation, reinforcement, and fairness and equity, are trying to prove how organizations can model employee behavior via the award systems and total compensation practices. (Vroom, 1964; Adams, 1963; Greenberg, 1990; Cowherd \& Levine 1992; Eisenhardt, 1989; Fama \& Jensen, 1983; Lambert \& Larcker, 1989) The theories of expectation and reinforcement are dedicated on the correlation between the expected employee behavior and the award that comes as a result of it. In other words, employee motivation is substantially influenced by what is expected because of a certain behavior, and how much value is added to that specific award. (Vroom, 1964). The theory of fairness and equity has major significance and affects all salary decisions, because to be fair and ethical and bring moral, consistent decisions for everyone is of critical value for all firms. This theory proposes that the award and compensation strategy should be completely aligned with the company's strategic objectives. (Adams, 1963; Cowherd \& Levine, 1992).

Apart from these traditional views, research continually shows that salary is not as significant indicator of measuring overall job satisfaction, as are the idiosyncrasies that embody a specific job and organization, its culture and environment. (Allen \& Bryant, 2012). One research that tried to 
compare and examine various reasons for leaving an organization, showed that upon comparing and measuring 35 different job satisfaction indicators, salary ranked $24^{\text {th }}$ on the list (Allen \& Bryant, 2012). Much research has already proven the well-known mantra that "people don't leave organizations, but they leave leaders" which underlines the valuable impact leaders have over people. The leader's influence and style are one of the most meaningful components in achieving high job satisfaction. Moreover, employees who receive more attention from their leaders feel more attached to the firm, more privileged, are generally more satisfied from the firm and are less likely to leave. (Graen \& Uhl-Bien, 1995).

Leaders are obliged to cascade the strategy and expectations, across the organization so employees can have clear path for professional growth and development. (Allen, et all., 2003). If employees believe the organization can provide them with professional growth, there is large probability they will be more committed and less likely to leave, even if they are not completely satisfied from the provided compensation and awards. Hence, firms should proactively manage the career paths and individual development, which helps strengthen the one's positive relationship with the organization. (Allen, et all., 2003).

In addition to close relationships with one's direct manager, strong team bonds have major influence in the overall job satisfaction, as they help increase one's positive emotional relation with the company. Therefore, it is the manager's responsibility to create platforms and opportunities for social interactions, support teamwork, enable new employees with creative onboarding (ways of entering in and learning about the organization), and to generate various positive experiences related to the workplace; so employees can be easily integrated, find their place in the company's future and ultimately show long-term commitment and loyalty (Mossholder, et all., 2005; Allen, 2006).

Employees are largely affected by their total remuneration package so, in addition to financial compensation they prefer other benefits such as: opportunity to purchase shares, private insurance plans, stable pension funds, professional development opportunities, travel, etc. (Dunford, et all, 2008)

\section{RESEARCH QUESTIONS AND HYPOTHESES}

This paper's subject matter elaborates on the effects of an equal-to-all salary raise, on the motivation and performance of sales professionals in the service industry's utterly competitive environment. It deeply analyses the effects from such salary increase, by measuring behavioral change prior to and after the announcement about the salary increase, in one key performance indicator in a particular employee group. The major challenge this research deals with is the knowledge gap, lack of awareness and data for sales professionals' motivation; as well as inclination to succumb to traditional beliefs and principles for their compensation.

Other significant managerial challenges, or habits, this research tries to address are: poor decisionmaking practices which are not based on data; improper problem-solving, which also lacks facts and application of the simplest, rather than the most effective solutions. How would this translate into practice? For instance, upon deciding how to award one's team, instead of identifying the most efficient, effective award strategy, the management decides to proceed with whatever 
solution seems easiest to be executed, without getting employee feedback or analyzing in what other manners the decision could be applied.

The research has both scientific and practical objectives. The major scientific objective is to diligently analyze effects, after announcing the salary raise to the sales professionals, on one of their key performance indicators. The effect on the respective KPI should also mirror the effect on their intrinsic motivation. One would think that logically, after receiving a salary raise, performance would be improved. Nonetheless, the research will try to prove that managers should be alert that such decisions are not universal; thus, are not effective in all organizations, and certainly not to all employees. Awards and compensation decisions should be customized per the specific business and workforce requirements. To have an optimal award and avoid adverse or no impact over motivation and performance, management needs to collect enough data for the specific traits of the job activities, the people who execute them and their talents. Ultimately, this would help identify one's genuine motivation factors. (Benabou and Tirole, 2003). The organizations need to carefully plan the total compensation and award system by implementing innovative and diverse solutions and strategies.

The practical objective of this paper is to apply the research results in the decision-making process regarding employees' compensation and awards (especially for sales teams). Thus, it was conducted in one international organization, which attempts to apply sophisticated reward systems for its sales team. This research general hypothesis is that equal and applicable-to-all salary increase for sales professionals, which does not reflect one's individual contribution and results does not improve performance. Consequently, it aims to respond to the following supporting hypothesis H1: There is statistical difference between the mean values of the KPIs prior to and after announcing the salary increase decision.

\section{MODELING THE TOTAL COMPENSATION SYSTEM (SALARY AND AWARDS)}

Today, award systems, as a positive business practice, offer plethora of possibilities and can be pinned down in almost every organization. The more sophisticated and mature the firm, the more complex hierarchy and award prospects it offers to its teams (Gibbons, 1997; Lazear, 2000; Rajan and Wulf, 2004). The business world is still far from having a universal formula which can be utilized in solving all motivational challenges. Thus, leaders are yet to face the most sensitive aspect of management, which is finding the most efficient and cost-effective manners of awarding their teams for the jobs they are performing. Awards are usually costly, either in financial or other dimensions, which keeps these challenges attractive even today. Empirical research shows that fixed salary is a tool that makes people feel secure and equal, although it is not enough to secure additional motivation for which managers must implement awards per performance and individual input. (Segalla et al., 2006) Nevertheless, there is scarcity of evidence and research about the effects of salary raise and its influence over performance and motivation. (De Ree, et all, 2017). Time and time again scholars and business practitioners have been trying to prove that compensation system based on individual input and performance (and not on fixed salary) guarantees performance improvement (De Ree, et all, 2017). Such belief almost justifies the 
variable costs that stem from having variable financial remuneration; and the necessity to correlate salary and performance, while ensuring that employees would be motivated enough to improve their performance in the future (Abowd, 1989).

Salary and other financial advantages bring direct financial benefits, larger chance for successful career and send positive signals into the (business) environment, which later grants positive financial advantage to the firm. (Kosfeld and Neckermann, 2011). By implementing appropriate awards, organizations get plenty of non-monetary advantages such as: increase in confidence, recognition, higher status in the group, etc. (Kosfeld and Neckermann, 2011). There is a diversity of awards can be provided, out of which professional development opportunities are the most preferred choice, especially with younger workforce (Islam and Ismail, 2004).

The process of modeling the award system ought to consider several multinational and multidisciplinary factors, as to avoid future challenges that might arise because of people's intrinsic, hidden values and beliefs (Segalla et al., 2006). Furthermore, while one award/recognition tool might be appropriate for one person, it can be completely inappropriate for another, depending on their personality and culture (Islam, and Ismail, 2004). An interesting cultural fact worth mentioning is that although applying performance-based award system is not novelty, it is far more adopted in the USA, than in the European countries. That is probably a consequence of the US traditional capitalistic, business values.

Furthermore, it is interesting to point out that although nowadays the organizational structure and managerial layers have become more decentralized and sophisticated; compensation and award decisions are still predominantly brought within the closed silos of the top, C-level management, boards or owners; while the middle management (including sales managers or directors) are included in the less costly awards, and mainly cascade top management decisions down the organization (Segalla et al., 2006).

Awards can also take symbolic meaning and forms, where their value is taken from the social and psychological benefits. (Auriol and Renault 2008). Notwithstanding the predominant opinion that financial awards always secure increased efforts, organizations ought to incorporate non-financial awards which comprise significant part of the contemporary motivational practices, such as organizing public events where medals, certificates and recognition are provided. (Nelson, 1994). Such awards have non-materials benefits and advantages and public awarding helps create even more competitive environment, which is especially needed in the sales environment (Kosfeld and Neckermann, 2011).

These ceremonies help recognize employees and distinguish elite groups, which are not only differentiated via their financial power, but through their privileged status in the organization. Logically, such status differences are in favor of those at the top of the pyramid who enjoy certain privileges, while could be discarded, and even decrease the motivation of those who have lower status (Kosfeld and Neckermann, 2011). Therefore, giving such recognition should not entirely replace financial awards. Generally, scholars and practitioners agree that people care about status, and so they take it into account upon deciding on the most appropriate non-financial awards, which 
may take diverse shapes such as: professional development opportunities, laptops, business phones, cars, fancy offices, travel opportunities, etc. (Auriol and Renault 2008)

While there are discrepancies and myriad ways of giving awards; and while some prefer to be publicly awarded, as employee of the month, and others would be satisfied by a simple thank you note, all effective awards share few common psychological traits. Once such important attribute is that the management must ensure everyone is well familiar with what an award represents; and what specifically leads to receiving it. It not, it might fail to reach the desired effect on people performance and motivation. (Bowen, 2000). Citing one employee, Bowen (2000) says "I was utterly embarrassed to be given the employee of the month award. I never knew what had I done to earn that award, and noticed that even my teammates were not too glad I had been nominated for it" (Bowen, 2000, p. 202).

In addition, awards ought to be aligned with people's specific experience and tenure. On the one hand, employees with shorter experience need not receive financial award and status. For them, motivation should arise from knowing their prosperous career path and professional growth. On the other hand, more experienced employees greatly appreciate any opportunities for growth and career development. They have already proven their value over the years, and as a result they should enjoy more prestigious awards and positions in the organization. Therefore, considering people's different preference, more experienced employees should receive packages that are comprised of both financial and non-financial awards (Bowen, 2000).

Reflecting on the overabundance of factors that impact award systems, it is recommended to implement awards that recognize: employees who are successfully running the most significant projects; initiatives that save costs or decrease expenses; team work efficiency and collaboration; high productivity and quality of work; innovation; customer care; highest achievements and sales; most successful teams; exceptional behavior in terms of organizational values, policies and behavior (Branham, 2001). Moreover, depending on the employee structure, management can implement creative awards, who could help employees improve their work-life balance. Organizations could offer awards that would provide employees with more quality free time in their private lives. For instance, such are: offering a healthy meal at work, which would enable them to spend the time they would cook a meal, on other meaningful free-time activity; or offering private kindergarten for parents, etc. (Oyer, 2008) In addition to these external awards, it is recommended to also apply internal awards whose benefits arise from conducting the job itself. These can take various shapes such as: assigning more meaningful job responsibilities; empowering employees and giving them more opportunities to directly impact their future; professional development and support in improving one's competencies; assigning challenging projects and activities which would ultimately lead to professional maturity; decision-making power; handover of various more diverse responsibilities per the employee specific interest and needs; providing opportunities to represent the organization on various public events; delegating tasks/projects that employees would prefer to do and find pleasure in doing; etc. (Bowen, 2000). It is worth mentioning that there are some scholars and theoreticians who claim that in the long run, awards do not necessarily positively impact employee performance. (Kruglanski, 1978; 
Koestner and Ryan, 1999; Wilson et. all, 1981) Or, awarding positive behavior weakens motivation and people should not be motivated by the award, but merely by conducting the job. Similarly, recent research shows that the process of giving up a certain habit (smoking or not pitting a seat belt while driving) should not be awarded. On the contrary, although initially awards may show success, they do not have a long-term positive impact over the entire process. (Kohn, 1993; Baron and Kreps, 1999) This research proves that there is more significant and longer success with those people who kicked-off a habit, without being incentivized by awards. By applying these principles into the business world, one can find theories who claim that award systems are rather demoralizing and diminishing motivation. (Kohn, 1993; Baron and Kreps, 1999, p. 99). Regardless, this research takes the completely opposite (and widely accepted) beliefs where awards are predominantly considered as a positive managerial practice, which positively impacts performance and motivation - with the important condition of - only if they are appropriately implemented.

\section{RESEARCH DATA, METHODOLOGY AND RESULTS}

To test the hypothesis, a practical test was conducted in the sales team of an international organization. More particularly, it examined the change in performance in a group of people, after they all were awarded with equal 10\% salary raise. The selected firm is an international institute for professional development, from the education industry. It predominantly works in the MENA region, where it provides various corporate development services and solutions, such as certified training programs and examinations. Its Skopje Office employs over 150 employees, out of which 100 are part of the sales and business development team, which was our focus group. Their major job purpose is to contact and build rapport with clients, and conduct sales presentations about the firm's services. By communicating with clients, they firstly invite respective professionals to a training course and organize their attendance to the event. Considering that clients are predominantly located in the MENA region, the entire communication is conducted mostly via phone (or email). To precisely measure the time spent communicating with clients via phone, the company utilizes a very sophisticated software, which determines the exact talking time spent on the phone, for each employee; where everyone is given a personal line. Logically, this talking time with clients is one of the KPIs for all sales employees in the firm; where the more junior the employee, the higher the expectations for this daily total talking time. After each working week (or five consecutive 8-hour working days), employees receive weekly reports via email, which include clear reports with exact talking time for each employee i.e. exactly how much time each of them spent talking on the phone with clients (see: Photo 1,2 and 3 columns 3,4,5,8,9 and 10 where talking time is expressed down to hours, minutes and seconds). This research examined the case when after few utterly successful quarters, the management decided to award all employees with 10\% salary increase; while not considering anyone's specific tenure, status, career development and progress, performance, achieved results, achieved KPIs, etc. Therefore, to prove the main and supporting hypothesis, we were focused on deeply analyzing this particular KPI. We took the average talking time for each employee three consecutive weeks prior to and after receiving the decision about the salary raise (see: Photo 1, 2, and 3). We considered the 
performance during this period of 30 employees, from all sales teams. The selected sample is comprised of 15 employees with less than 2 years' experience (Juniors) and 15 with more than two years' experience (Seniors), out of which some are also Team Leaders and responsible for managing small teams.

Table 1: Research Structure - Prior to announcing the award

\begin{tabular}{|c|c|c|c|c|c|c|c|}
\hline \multicolumn{3}{|c|}{ Employee data } & \multicolumn{5}{|c|}{ Weekly KPI (Call Rates) BEFORE the announcement } \\
\hline & Samples & $\begin{array}{l}\text { Date of } \\
\text { employment }\end{array}$ & $30.06-04.07$ & $07.07-11.07$ & $14.07-18.07$ & Average & $\begin{array}{c}\text { Ave in } \\
\text { Minutes }\end{array}$ \\
\hline \multirow{15}{*}{ 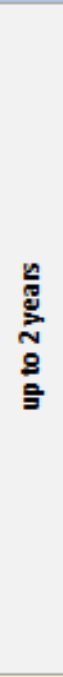 } & Employee 1 & $19 / 2 / 2019$ & $06: 50: 12$ & 07:03:49 & $08: 48: 49$ & $07: 34: 17$ & 454.28 \\
\hline & Employee 2 & $1 / 4 / 2019$ & $04: 16: 15$ & $04: 51: 56$ & $04: 35: 49$ & $04: 34: 40$ & 274.67 \\
\hline & Employee 3 & $1 / 4 / 2019$ & 01:06:04 & $02: 20: 29$ & 04:31:05 & 02:39:13 & 159.21 \\
\hline & Employee 4 & $1 / 4 / 2019$ & 05:03:52 & $06: 29: 25$ & $03: 44: 14$ & $05: 05: 50$ & 305.84 \\
\hline & Employee 5 & $28 / 1 / 2019$ & 03:01:11 & $04: 57: 02$ & $04: 46: 49$ & $04: 15: 01$ & 255.01 \\
\hline & Employee 6 & $1 / 8 / 2018$ & $3: 07: 37$ & $03: 27: 53$ & $4: 06: 18$ & $03: 17: 45$ & 197.75 \\
\hline & Employee 7 & $1 / 8 / 2018$ & $3: 26: 58$ & $3: 23: 21$ & $04: 25: 32$ & $03: 56: 15$ & 236.25 \\
\hline & Employee 8 & $10 / 8 / 2018$ & $3: 41: 00$ & 03:31:59 & $00: 00: 16$ & 01:46:07 & 106.13 \\
\hline & Employee 9 & $10 / 8 / 2018$ & $1: 25: 30$ & $01: 33: 48$ & $1: 09: 28$ & 01:29:39 & 89.65 \\
\hline & Employee 10 & $18 / 8 / 2018$ & $0: 44: 58$ & 03:03:03 & $03: 47: 06$ & $02: 31: 42$ & 151.71 \\
\hline & Employee 11 & $18 / 8 / 2018$ & $2: 48: 17$ & $2: 42: 04$ & $00: 02: 03$ & $00: 02: 03$ & 2.05 \\
\hline & Employee 12 & $18 / 8 / 2018$ & $4: 32: 22$ & $05: 02: 22$ & 05:00:39 & 05:01:31 & 301.51 \\
\hline & Employee 13 & $3 / 5 / 2017$ & $02: 37: 20$ & $4: 14: 41$ & $03: 13: 23$ & $02: 55: 21$ & 175.36 \\
\hline & Employee 14 & $25 / 10 / 2017$ & $05: 10: 38$ & $5: 24: 44$ & $05: 52: 40$ & 05:31:39 & 331.65 \\
\hline & Employee 15 & $25 / 12 / 2017$ & $05: 10: 06$ & $05: 58: 12$ & $05: 10: 20$ & $05: 26: 13$ & 326.21 \\
\hline \multirow{15}{*}{$\underset{\substack{n\\
}}{\stackrel{n}{*}}$} & Employee 16 & $1 / 3 / 2016$ & $2: 35: 39$ & $02: 20: 02$ & $02: 34: 27$ & $02: 27: 14$ & 147.24 \\
\hline & Employee 17 & $27 / 10 / 2016$ & $02: 58: 03$ & $03: 45: 28$ & 02:32:05 & 03:05:12 & 185.20 \\
\hline & Employee 18 & $27 / 10 / 2016$ & $01: 59: 57$ & $01: 17: 53$ & $01: 42: 38$ & 01:40:09 & 100.16 \\
\hline & Employee 19 & $1 / 11 / 2016$ & $2: 41: 35$ & $00: 00: 34$ & $03: 46: 21$ & $01: 53: 27$ & 113.46 \\
\hline & Employee 20 & $25 / 11 / 2015$ & $03: 41: 00$ & $04: 26: 32$ & $02: 57: 29$ & $03: 41: 40$ & 221.67 \\
\hline & Employee 21 & $16 / 6 / 2015$ & $1: 12: 02$ & $02: 32: 58$ & $04: 05: 13$ & 03:19:06 & 199.09 \\
\hline & Employee 22 & $1 / 10 / 2015$ & $03: 29: 51$ & $02: 56: 49$ & $03: 37: 37$ & $03: 21: 26$ & 201.43 \\
\hline & Employee 23 & $16 / 1 / 2015$ & $4: 43: 58$ & $02: 53: 33$ & $01: 12: 18$ & $02: 02: 56$ & 122.93 \\
\hline & Employee 24 & $11 / 9 / 2012$ & 03:01:21 & $2: 21: 00$ & $02: 21: 43$ & $02: 41: 32$ & 161.53 \\
\hline & Employee 25 & $18 / 9 / 2013$ & $00: 41: 44$ & $00: 30: 12$ & 01:30:09 & $00: 54: 02$ & 54.03 \\
\hline & Employee 26 & $1 / 12 / 2013$ & 01:43:45 & $02: 42: 26$ & $02: 54: 01$ & $02: 26: 44$ & 146.73 \\
\hline & Employee 27 & $1 / 1 / 2014$ & $01: 10: 22$ & $02: 51: 17$ & $02: 05: 34$ & $02: 02: 24$ & 122.41 \\
\hline & Employee 28 & $4 / 9 / 2014$ & $04: 39: 43$ & 04:01:04 & $04: 00: 29$ & $04: 13: 45$ & 253.76 \\
\hline & Employee 29 & $25 / 4 / 2014$ & $01: 06: 32$ & $02: 31: 14$ & $03: 41: 46$ & $02: 26: 31$ & 146.51 \\
\hline & Employee 30 & $4 / 9 / 2014$ & $02: 40: 15$ & $02: 11: 02$ & $02: 40: 10$ & $02: 30: 29$ & 150.48 \\
\hline
\end{tabular}

Source: Authors own calculations 
Table 2: Research Structure - After announcing the award

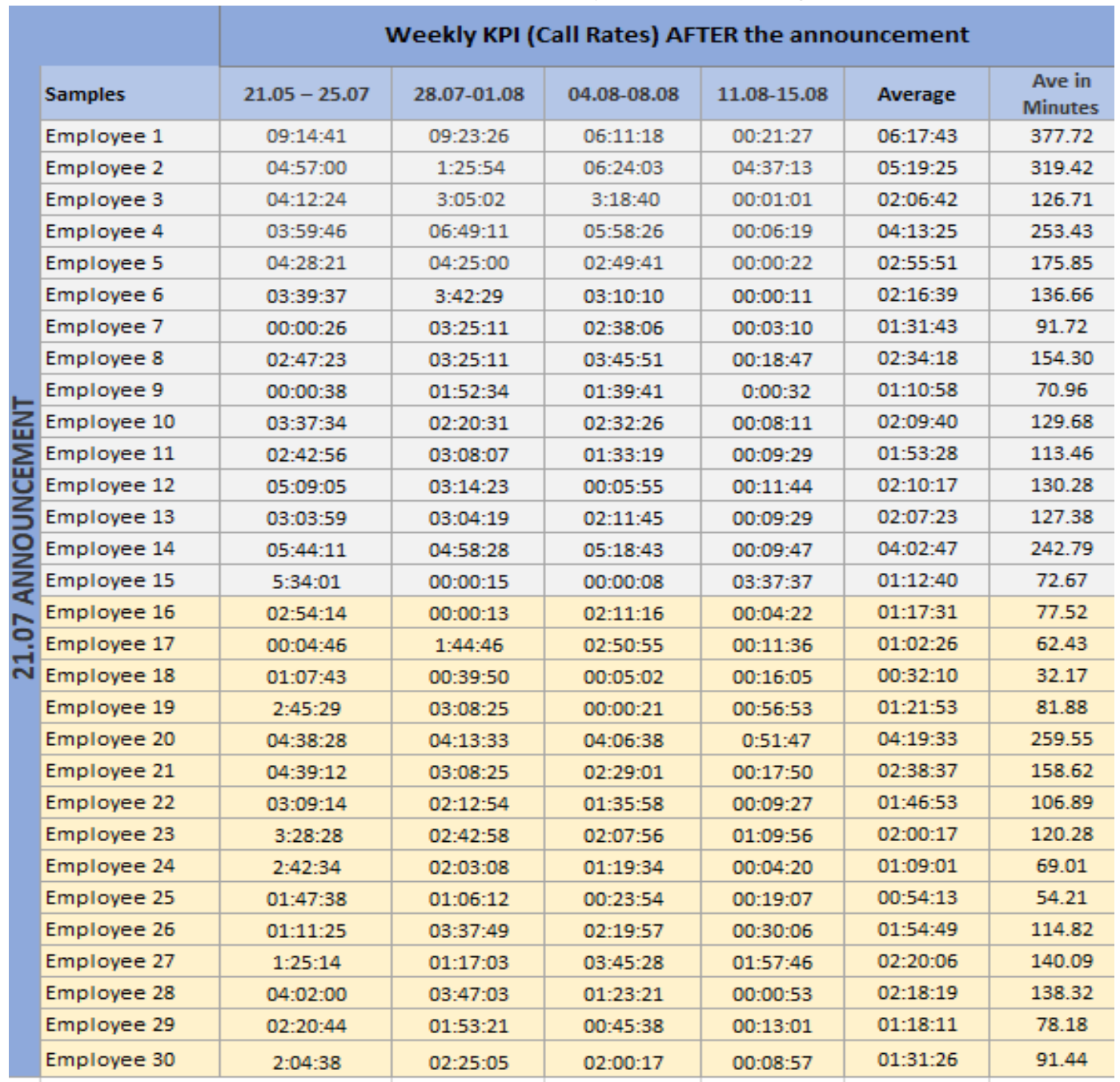

Source: Authors own calculations 
Table 3: Research Structure - Results

\begin{tabular}{|c|c|c|c|}
\hline \multicolumn{4}{|c|}{ Results } \\
\hline Results & $\begin{array}{l}\text { Difference } \\
\text { in Hours }\end{array}$ & $\begin{array}{c}\text { What \% } \\
\text { is } M \text { from G }\end{array}$ & $\begin{array}{l}\text { Difference } \\
\text { in minutes }\end{array}$ \\
\hline down & $01: 16: 34$ & 0.17 & 76.56 \\
\hline up & na & -0.16 & -44.76 \\
\hline down & $00: 32: 30$ & 0.20 & 32.50 \\
\hline down & $00: 52: 25$ & 0.17 & 52.41 \\
\hline down & $01: 19: 10$ & 0.31 & 79.16 \\
\hline down & 01:01:06 & 0.31 & 61.09 \\
\hline down & $02: 24: 32$ & 0.61 & 144.53 \\
\hline up & na & -0.45 & -48.18 \\
\hline down & $00: 18: 41$ & 0.21 & 18.69 \\
\hline down & $00: 22: 02$ & 0.15 & 22.03 \\
\hline up & na & -54.35 & -111.41 \\
\hline down & $02: 51: 14$ & 0.57 & 171.23 \\
\hline down & $00: 47: 59$ & 0.27 & 47.98 \\
\hline down & $01: 28: 52$ & 0.27 & 88.86 \\
\hline down & $04: 13: 33$ & 0.78 & 253.54 \\
\hline down & 01:09:43 & 0.47 & 69.72 \\
\hline down & $02: 02: 46$ & 0.66 & 122.77 \\
\hline down & 01:07:59 & 0.68 & 67.99 \\
\hline down & $00: 31: 34$ & 0.28 & 31.58 \\
\hline up & na & -0.17 & -37.88 \\
\hline down & $00: 40: 29$ & 0.20 & 40.48 \\
\hline down & $01: 34: 32$ & 0.47 & 94.54 \\
\hline equal & $00: 02: 39$ & 0.02 & 2.65 \\
\hline down & $01: 32: 31$ & 0.57 & 92.52 \\
\hline equal & na & 0.00 & -0.18 \\
\hline down & $00: 31: 55$ & 0.22 & 31.91 \\
\hline up & na & -0.14 & -17.69 \\
\hline down & $01: 55: 26$ & 0.45 & 115.43 \\
\hline down & $01: 08: 20$ & 0.47 & 68.33 \\
\hline down & $00: 59: 03$ & 0.39 & 59.04 \\
\hline
\end{tabular}

Source: Authors own calculations

Regarding the applied methodology, hypothesis were tested via the statistical $T$-test, predominantly utilized upon using a specific group; and tests whether there are statistical differences in the results, or they are random. More precisely, it is utilized to define whether one can find significant difference in the analyzed KPI for the selected group of 30 sales employees, prior to and after receiving the announcement about the salary increase. The larger the $\mathrm{T}$ value, the higher the difference between the median of both samples. More precisely, by applying the Ttest, one can identify if there are significant statistical differences between the results' median prior to and after the salary increase. Should the test prove there are statistical differences, one can confirm the research hypothesis.

HO Hypothesis: By comparing the medians (middle values) one cannot find statistical differences prior to and after announcing the salary increase. 
H1 Hypothesis: By comparing the average value one can find statistical difference prior to and after announcing the salary increase.

The test rejects the $\mathrm{H} 0$ and confirms there are statistical differences, since the test statistic is larger than the appropriate critical value for the given value of alpha $(\alpha)$. That is, when the $p$-value is smaller than alpha $\alpha(\mathrm{p}<\alpha)$.

Usually, the level of significance is $\alpha=0,05$. The hypothesis difference in the medium value is 0 , which means that it is assumed that there is no significant statistical change in the key performance indicator which was analyzed. The level of $\alpha$ remains 0.05 , as a standard for similar tests. The research results are represented in more detail in the table below (Photo 4).

Table 4: T-test results

\begin{tabular}{l|r|r}
\hline & Variable 1 & Variable 2 \\
\hline Mean & 189.7962037 & 136.9475463 \\
\hline Variance & 8886.911437 & 6430.748583 \\
\hline Observations & 30 & 30 \\
\hline Pearson Correlation & 0.677665037 & \\
\hline Hypothesized Mean Diff $\epsilon$ & 0 & \\
\hline$d f$ & 29 & \\
\hline$t$ Stat & 4.064586812 & \\
\hline$P(T<=t)$ one-tail & 0.000167808 & \\
\hline C Critical one-tail & 1.699127027 & \\
\hline$P(T<=t)$ two-tail & 0.000335617 & \\
\hline$t$ Critical two-tail & 2.045229642 & \\
\hline
\end{tabular}

Source: Authors own calculations

Upon applying the T-test, the $\mathrm{P}$ value $(0,000167808)$ is compared with the value of $\alpha$ which is set as a parameter (0.05). If this value is smaller than $\alpha$ (which in our case it is), the H0 is rejected. More specifically, we can prove there are no significant changes in the analyzed KPI, which is this research's subject matter. Consequently, it can be concluded there is statistical difference in the median (middle values) prior to and after announcing the decision.

Moving on to the research, one can conclude that this two-tail test proves only if there are or are not changes in the median (middle values). In order to prove whether the change has been toward improvement or decent, one tail test had been applied which shows whether the key performance indicator, which was analyzed via the research, has improved or degraded after the announcement about the salary raise.

HO Hypothesis: Performance remained the same, after the management's public announcement about the salary increase, applicable and equal to all employees.

H1 Hypothesis: Performance has deteriorated, after the management's public announcement about the salary increase, applicable and equal to all employees. (M1-M2 > 0, M1 and M2 are average of the KPI). 
For this purpose, another test was conducted; M1-M2 whose parameters are widely utilized in statistical analysis were created. The following formula was utilized to calculate the T-value:

$T=(X d$ - hypothesized $) /(S d / S Q R T(n))$ whereby $X d$ is the average of the differences in the KPI differences, and $S d$ is the standard deviation from the differences in the KPI. The value of the hypotheses is equal to 0 , because according to $\mathrm{H} 0$ no changes had been identified. By utilizing mathematical calculations, we receive the $\mathrm{T}$ value of 4.064586812 .

Afterwards, we calculate the P value, via the function T.DIST.RT (T,Dof), where Dof represents the degrees of freedom where the value of P equals 0.00017. Since P's value is smaller than the $\alpha$ 's starting value (which is usually 0.05 ), we can reject the hypothesis that there have not been changes in the analyzed key performance indicator thus, accepting the hypothesis that there are changes in the key performance indicator and the results had deteriorated.

The meticulous research, elaborated above, helps conclude the following:

- Upon measuring metrics in the selected KPI, one cannot identify a positive boost in performance for sales teams prior to and after they have been notified on an equal-to-all salary raise.

- Considering one cannot identify performance improvement, it can be concluded that awarding sales professionals via equal-to-all salary raise, regardless of their individual contribution, cannot result in improved performance; regardless of the fact the firm would need to set aside large budget to execute the decision.

- The research, which included 30 employees, showed that the analyzed KPI, not only had not improved, but it many cases worsened. Only 5 employees have shown improvement, where only 2 had sustained the same level of performance. This fact underlines the conclusion that the award had not positively affected motivation and performance.

- Upon analyzing any consequences of the salary increase, one can conclude that neither tenure or overall experience contribute to performance. Or, salary raise did not positively affected: less experienced employees (Juniors), employees with few years' experience (Seniors) and employees with managerial roles (Team Leads).

\section{RESEARCH LIMITATIONS}

Although the research is aligned with the defined hypothesis and supporting hypothesis, it is necessary to emphasize few limitations, which predominantly arise from a technical viewpoint. Firstly, it is based on a single KPI, which limits its scope. The effect of the salary raise could have influenced other KPIs such as: number of sent emails (which can also show daily outreach to clients); the quality of the presentations which were conducted at that time, since shorter talking time does not necessarily mean that the conversations per se were less efficient i.e. the quality of the pitches could have surpassed its quantity (talking time).

Moreover, the research comes down to the fact that the effect of the salary raise should be immediately distinguishable. Awards could have affected other psychological, internal territories, and be far more than something that can be simply measured through the KPIs. Similarly, the 
research could further evaluate what were the effects on the firm's culture, the general perception on its brand, loyalty, job satisfaction, level of security provided to employees, etc.

Another limitation could potentially be the sample size and structure as it was based on ample of 30 people. If the total number of sales employees is considered, one might question the sample size. Regardless, it is safe to scientifically assume that a sample of 30 employees is enough to represent relevant and fact-based data. The sample satisfies the required resources and time necessary to conduct a thorough and all-encompassing research, based on sample which is large enough to have people with different backgrounds and profiles. Moreover, the research sample includes employees that fall under different groups, more specifically: employees from different gender, age, working experience as well as employees from all sectors within the sales and business development team.

Other direct quantitative indicators, which might have been affected by the award and which could help in shaping a more comprehensive statistical and econometric analysis (such as the culture or the employees' subjective perceptions about the organization), are almost non-existent. Thus, it can be concluded that the statistical data which was applied, successfully provided solid foundation for reaching the above conclusions.

\section{CONCLUSION}

This paper contributes to the discipline of HRM by helping scholars and business practitioners understand that traditional systems for total compensation and awards are not sustainable for contemporary firms, especially to those who employ younger workforce. Awarding equal-andapplicable-to-all, minor salary raise is not an efficient practice that improves performance or motivation. The paper helps corelate the acumen from similar research, from eminent authors, to emphasize the fact that small, non-monetary awards, or awards which are individual and performance-based can have a lot greater impact over motivation and performance.

The main conclusion from the research is that implementing proper award systems has large influence over performance, especially for employees whose remuneration package is variable per their individual input, achievements, and results. Also, any award's specific purpose and criteria (requirements to receive the award considering accomplishment of specific KPI over a time) should always be transparently shared with the team and precede its implementation.

Nonetheless, it is important to note that the research does not want to prove that salary is not important, or that monetary awards do not influence performance. On the contrary, it is trying to prove that non-monetary awards can help create a perfect whole, and has the power to design optimal, personalized system for awarding and compensating teams, while being based on both financial and non-financial awards (Auriol and Renault 2008). Managers and HRM involved in reward management are responsible to build a high-performance culture by delivering awards and pay for performance programs that recognize and reward critical (sales) skills, strong (business development) capabilities, experience and performance, and ensure that reward systems are market based, equitable and cost effective (Armstrong 2010). 


\section{REFERENCES}

Adams, J.S., (1963), Toward an understanding of inequity. Journal of Abnormal Psychology, 67, p. $422-436$.

Allen, D. G. (2006). Do organizational socialization tactics influence newcomer embeddedness and turnover? Journal of Management, 32, 237-256.

Allen, D. G., \& Bryant, P. C. (2012). Managing employee turnover: Dispelling myths and fostering evidence-based retention strategies. New York, NY: Business Expert Press

Allen, D. G., Shore, L. M., \& Griffeth, R. W. (2003). The role of perceived organizational support and supportive human resource practices in the turnover process. Journal of Management, 29, 99118.

Armstrong, M. (2010), Armstrong's handbook of reward management practice: improving performance through reward, $3^{\text {rd }}$ edition, Kogan Page, London.

Ariely, D., Bracha, A., and Meier, S., (2009), Doing Good or Doing Well? Image Motivation and Monetary Incentives in Behaving Prosocially, American Economic Review, 99 (1), p. $544-555$.

Auriol, E. and Renault, R., (2008), Status and Incentives, The RAND Journal of Economics, 39 (1), 305-326.

Ball, S., Eckel, C.K., Grossman, J.P., and Zame, W., (2001), Status in Markets, Quarterly Journal of Economics, 116 (1), p. 161-188.

Baron, J.N., \& Kreps, D.N., (1999), Strategic Human Resources, New York: Wiley.

Benabou, R., Tirole, J., (2003), Intrinsic and Extrinsic Motivation, Review of Economic Studies, 70(3), p.489-520.

Besley, T., Maitreesh G., (2008), Status Incentives, American Economic Review,98 (2), 206-211. Bojadzioski, D., Eftimov, L. (2009), Human resource management, (in Macedonian), Faculty of economics-Skopje.

Bowen, B. R., (2000), Recognizing and Rewarding Employees, McGraw Hill, New York.

Bradler, D., Dur, R., Neckermann, S. and Non, A. (2013). Employee Recognition and Performance: A Field Experiment, ZEW- Centre for European Economic Research, Discussion Paper No. 13-017.

Branham, L., (2001), Recognize result, Executive Excellence, July, p. 17-18.

Broberg, T., Ellingsen, T. and Johannesson, M., (2007), Is generosity involuntary?, Economics $\begin{array}{llllll}\text { Letters, } 94, \quad \text { issue } & 1, & \text { p. }\end{array}$ https://EconPapers.repec.org/RePEc:eee:ecolet:v:94:y:2007:i:1:p:32-37

Bryant, P., Allen, D., (2013). Compensation, Benefits and Employee Turnover HR Strategies for Retaining Top Talent, Compensation \& Benefits Review, 45. 171-175. $10.1177 / 0886368713494342$.

Cowherd, D.M., \& Levine, D.I. (1992), Product quality and pay equity between lower-level employees and top management: An investigation of distributive justice theory, Administrative Science Quarterly, 37, p. 302-320. 
Dal Bó, E., Finan, F., Rossi, M.A. , (2013), Strengthening State Capabilities: The Role of Financial Incentives in the Call to Public Service, The Quarterly Journal of Economics, Oxford University Press, vol. 128(3), pages 1169-1218.

De Ree, J., Muralidharan, K., Pradhan, M., Rogers, H., Double for Nothing? Experimental Evidence on an Unconditional Teacher Salary Increase in Indonesia, The Quarterly Journal of Economics, Volume 133, Issue 2, May 2018, Pages 993-1039, https://doi.org/10.1093/qje/qjx040 Deci, E., Koestner, R. and Ryan, R. (1999), A Meta-Analytic Review of Experiments Examining the Effects of Extrinsic Rewards on Intrinsic Motivation, Psychological Bulletin, Emerald Group Publishing Limited, 125 (6), p. 627-668,

Dubey, P. \& Geanakoplos, J. (2006), Grading in Games of Status: Marking Exams and Setting Wages.

Dunford, B. B., Oler, D. K., \& Boudreau, J. W., (2008). Underwater stock options and voluntary executive turnover: A multidisciplinary perspective integrating behavioral and economic theories., Personnel Psychology, 61, p. 687-726

Dur, R., (2009), Gift Exchange in the Workplace: Money or Attention?, Journal of the European Economic Association, 7 (2-3), p. 550-560.

Ederer, F. and Patacconi, A., (2008), Interpersonal Comparison, Status and Ambition in Organizations, Mimeo, MIT and Oxford

Eisenhardt, K.M., (1989), Agency Theory: An assessment and Review. Academy of Management Review, 14, 57-74

Falk, A., (2007), Gift Exchange in the Field, Econometrica, 75, p. 1501-1511.

Fama, E.F., \& Jensen, M.C., (1983)., Separation of Ownership and Control. Journal of Law and Economics, 26, 301-325.

Fehr, E., Gachter, S., and Kirchsteiger G., (1997), Reciprocity as a Contract Enforcement Device: Experimental Evidence, Econometrica, 65, p.833-860.

Fehr, E., Kirchsteiger G., and Riedl, A., (1993), Does Fairness Prevent Market Clearing - an Experimental Investigation, Quarterly Journal of Economics, 108, p.437-459.

Frey, B.S., (2007), Awards as Compensation European Management Review, Vol. 4, Issue 1, University of Basel, p. 6-14,

Gibbons, R. (1997), Incentives and Careers in Organizations, in D. Kreps and K. Wallis (eds.) Advances in Economic Theory and Econometrics, Vol. II (Cambridge, U.K.: Cambridge University Press).

Graen, G. B., \& Uhl-Bien, M. (1995)., The relationship-based Approach to Leadership: development of LMX Theory of Leadership over 25 years: Applying a multilevel, multi-domain perspective. Leadership Quarterly, 6, p. 219-247

Greenberg, J., (1990), Employee theft as a reaction to underpayment of inequity: The hidden cost of pay cuts, Journal of Applied Psychology, 75, p. 561-568.

Islam, R. and Ismail, A. (2004): Ranking of employees' reward and recognition approaches: $A$ Malaysian Perspective. Published in: Journal of International Business and Entrepreneurship Development, Vol. 2, No. 2 (2004): p. 113-124. 
Kohn, A. (1993), Punished by Rewards, New York: Plenum Press.

Kosfeld, M., and Neckermann, .,(2011), Getting More Work for Nothing? Symbolic Awards and Worker Performance, American Economic Journal: Microeconomics, 3 (3): 86-99.DOI: 10.1257/mic.3.3.86

Kruglanski, A., (1978), Issues in Cognitive Social Psychology, in The Hidden Cost of Reward: New Perspectives on the Psychology of Human Motivation (New York: John Wiley).

Lambert, R.A., \& Larcker, D.F., (1989)., Executive Compensation, Corporate Decision-making, and Shareholder Wealth. In F. Foulkes (Ed.), Executive compensation (pp. 287-309). Boston: Harvard Business School Press.

Lazear, E. (2000), Performance, Pay and Productivity, American Economic Review, 90 (5), p.1346-1361.

Markham, S.E., Dow S. K., and McKee, H.G., (2002), Recognizing Good Attendance: A Longitudinal, Quasi-Experimental Field Study, Personnel Psychology, 55 (3), p. 639-660.

McGovern, P, Smeaton, D, Hill, S (2004), Bad jobs in Britain. Work and Occupations, 31(2): 22549. Google Scholar, SAGE Journals, ISI

Moldovanu, B., Aner S., and Xianwen S, (2007), Contests for Status, Journal of Political Economy, 115 (2), p. $338-363$.

Mossholder, K. W., Settoon, R. P., \& Henagan, S. C. (2005)., A Relational Perspective on Turnover: Examining Structural, Attitudinal, and Behavioral Predictors. Academy of Management Journal, 48, p. 607-618.

Oyer, P., (2008), Salary or benefits?, Polachek, S. and Tatsiramos, K. (Ed.) Work, Earnings and Other Aspects of the Employment Relation (Research in Labor Economics, Vol. 28), Emerald Group Publishing Limited, Bingley, p. 429-467. https://doi.org/10.1016/S0147-9121(08)28013-1 Rajan, R.G. and Wulf, J., (2006), Are Perks Purely Managerial Excess?, Journal of Financial Economics, Volume 79, p. 1-33

Segalla, M., Rouziès, D., Besson, M. and Weitz, B., (2006)., A cross-national investigation of incentive sales compensation, International Journal of Research in Marketing, [online] 23(4), p.419-433. Available at: https://studies2.hec.fr/jahia/webdav/site/hec/shared/sites/Segalla/acces_anonyme/A\%20crossnational\%20investigation $\% 20$ of $\% 20$ incentive $\% 20$ sales $\% 20$ compensation.pdf.

Vroom, V.H., (1964), Work and Motivation. New York: Wiley.

Wilson, T., Hull, J. and Johnson, J. (1981), Awareness and Self-Perception: Verbal Reports on Internal States, Journal of Personality and Social Psychology, 40, p.53-71. 